\title{
Temperature and Precipitation Trends in Belgrade and Indicators of Changing Extremes for Serbia
}

\author{
Smilja V. Đorđević ${ }^{1}$ \\ Received: June 2008 | Revised: August 2008 | Accepted: August 2008
}

\begin{abstract}
Deviations and trends are analysed of seasonal and annual mean and extreme air temperatures, precipitation sums and the number of days with precipitation in Belgrade for the longer period of 1888-2006 for the purpose of recording climate changes.

On the territory of Serbia, climate changes were monitored by the calculation of the indicators of changing extremes for temperature on 15 stations in the shorter period of 1957-2006 and for precipitation on 19 stations for the period 1961-2006. These climate extreme indices include the extremely hot days, cold days, warm nights, cold nights, the heat wave duration end the annual fraction due to extreme precipitation events.
\end{abstract}

Key words: extreme climate indices; heat wave; extreme precipitation events; tendency analysis; climate change detection.

\section{Introduction}

Climate changes due to global warming are unmistakable. This can be seen in the rise of global mean air and ocean temperatures, increasing intensity of permafrost melting as well as in the increase in mean sea level (Climate Change, 2007).

In this paper indicators of climate changes were obtained using two methods. The first method was used to analyse deviations, 5-year moving means and trends of seasonal and annual mean, minimum and maximum air temperatures, precipitation sums and number of days with precipitation for Belgrade in the period 1888-2006, (WMO, 1983). The other method meant the observation of climate changes in Serbia by calculating the indicators of changing extremes (Djordjevic, 2002; Djordjevic and Jovanovic, 2006; Jovanovic and Djordjevic, 2006) defined by the World Meteorological Organization (Peterson, et al., 2001). This method was applied on 15 main stations for the temperature in the period 1957-2006 and on 19 main stations for the precipitation in the period 1961-2006.

\section{Methodology and data}

Daily climatological data on air temperature and precipitation quantity were used. All the anomalies were calculated for each year in relation to the basic period 1961-1990 and then trend lines were assessed by the least square method. Percentiles were used for obtaining the range of normal and extreme temperature and precipitation values (WMO, 1983).
Critical values of temperature and precipitation in percentiles are shown in Table 1. Homogeneity has not been done. Available data have been used in such form for all climate analyses so far.

Table 1 Critical values of temperature and precipitation in percentiles

\begin{tabular}{|c|c|c|}
\hline Percentiles & Air temperature & Precipitation \\
\hline 1 & extremely cold & extremely dry \\
\hline $2-9$ & very cold & very dry \\
\hline $10-24$ & cold & dry \\
\hline $25-75$ & normal & normal \\
\hline $76-90$ & hot & humid \\
\hline $91-98$ & very hot & very humid \\
\hline 98 & extremely hot & extremely humid \\
\hline
\end{tabular}

On 15 stations in Serbia for the period 1957-2006, the following indicators of changing extremes for temperature were calculated (Peterson, et al., 2001), as listed with their shortened names:

1. Tn9o, that represents minimum temperature above the $90^{\text {th }}$ percentile with the meaning of very high values of minimum temperature,

2. Tn1o, that represents minimum temperature below the $10^{\text {th }}$ percentile with the meaning of very low values of minimum temperature, 
3. Tx9o, that represents maximum temperature above the $90^{\text {th }}$ percentile with the meaning of very high value of maximum temperature,

4. Tx10, that represents maximum temperature above the $10^{\text {th }}$ percentile with the meaning of very low value of maximum temperature,

5. HWDI, that represents maximum number of consecutive days during the year with the maximum temperature $5^{\circ} \mathrm{C}$ above the $1961-90$ daily normal or so-called heat waves,

6. TxGE30, that represents days when maximum temperature is $\geq 30^{\circ} \mathrm{C}$.

For 19 stations in Serbia precipitation indicator was calculated for the period 1961-2006,

7. $\mathrm{R}_{95} \mathrm{~T}$, that represents the fraction of annual total precipitation due to events exceeding the $95^{\text {th }}$ percentile.

Besides mentioned indicators, average values were also calculated of the indicators of changing extremes from (1) to (7) for the basic period 1961-1990, deviations from average values for each individual year and trend of these deviations.

\section{Results}

\section{Belgrade - Temperature}

Deviation of mean annual, maximum and minimum temperatures from the basic period 1961-1990 are shown in three panels of Figure 1 going downwards. Also, black curves show 5-year moving means, and straight lines are temperature trends. Besides the mentioned, trend equations are given where $T_{\text {mean }}, T_{\max }$ and $T_{\text {min }}$ are mean, maximum and minimum temperature and $t$ is a year. Slope coefficient
Table 2 Deviation trend coefficients as per seasons of mean, maximum and minimum temperatures in Belgrade in the period of $1888-2006$

\begin{tabular}{|l|c|c|c|}
\hline Seasons & $\begin{array}{c}\mathbf{T}_{\text {mean }} \\
\left({ }^{\circ} \mathrm{C} / 100 \text { years }\right)\end{array}$ & $\begin{array}{c}\mathbf{T}_{\text {max }} \\
\left({ }^{\circ} \mathrm{C} / 100 \text { years }\right)\end{array}$ & $\begin{array}{c}\mathbf{T}_{\text {min }} \\
\left({ }^{\circ} \mathrm{C} / 100 \text { years }\right)\end{array}$ \\
\hline Spring & +1.32 & +0.54 & +1.92 \\
\hline Summer & +1.04 & -0.02 & +1.95 \\
\hline Autumn & +0.74 & +0.31 & +1.69 \\
\hline Winter & +1.95 & +1.68 & +2.97 \\
\hline
\end{tabular}

of straight line is called temperature trend coefficient and serves as the assessment of temperature change tendency.

Significant positive temperature trend coefficients are observed in all three cases. Thus, in observed period, the rise of mean, maximum and minimum annual air temperature was prominent. Among all the cases, trend coefficient has the highest value for minimum temperature in the amount of $+2.10^{\circ} \mathrm{C} / 100$ years. This shows that the rise of minimum temperature was the greatest.

Coefficient of trends as per seasons (first column) of mean (second column), maximum (third column) and minimum (fourth column) temperatures are shown in this order in Table 2. It is evident that in all cases trend coefficients are positive, except in summer season with maximum temperature when the trend value is slightly below zero. Thus mostly mean, maximum and minimum seasonal air temperatures have risen, except in summer when maximum temperature showed the tendency of slight decrease. Out of all seasons, winter has the highest value of trend coefficient for minimum temperatures when the highest value of $+2.97^{\circ} \mathrm{C} / 100$ years was obtained. This shows that the rise of minimum temperature is the highest during winter.

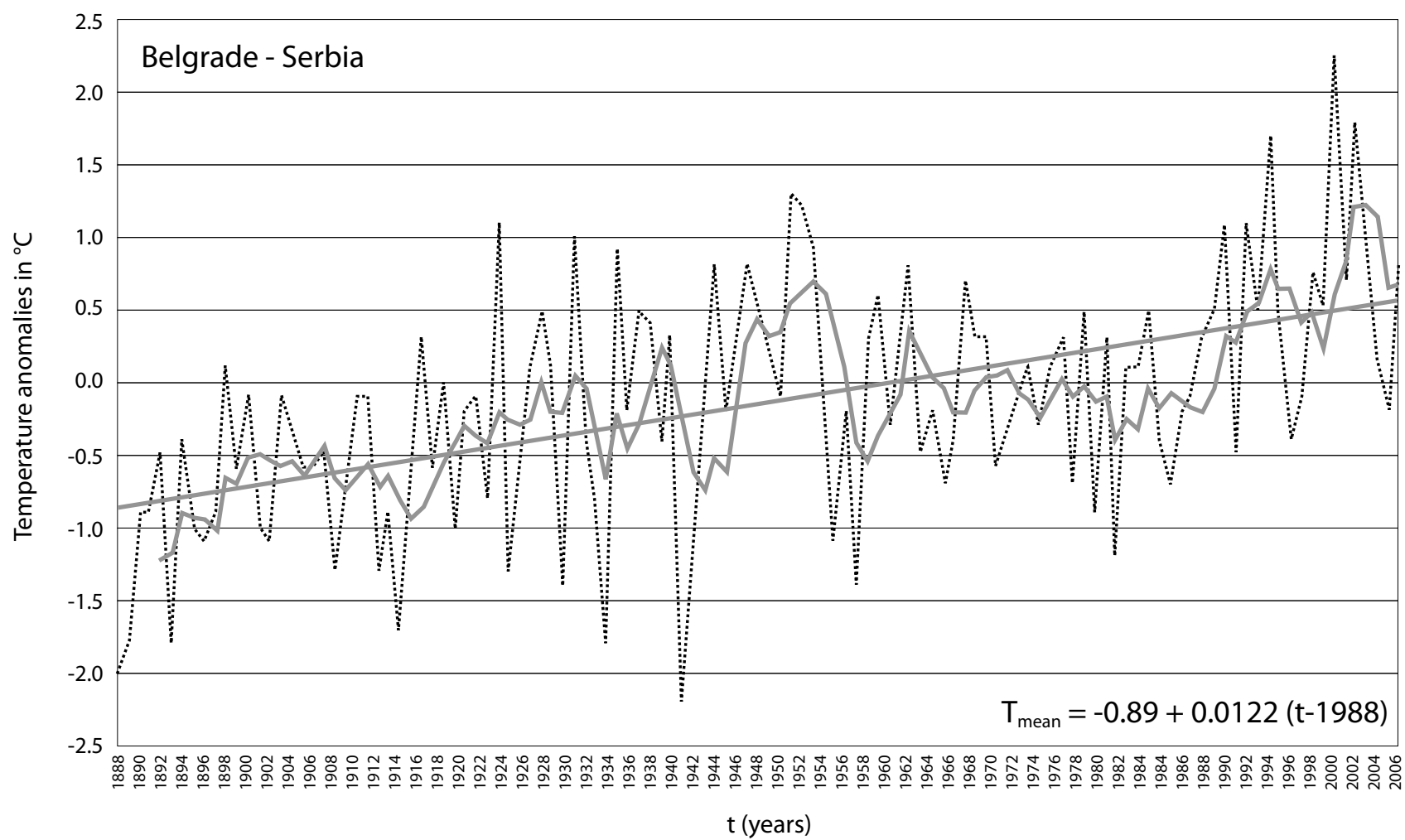

Figure 1a Deviation, 5-year moving means and deviation trends of annual mean temperature for Belgrade for the period $1888-2006$ 


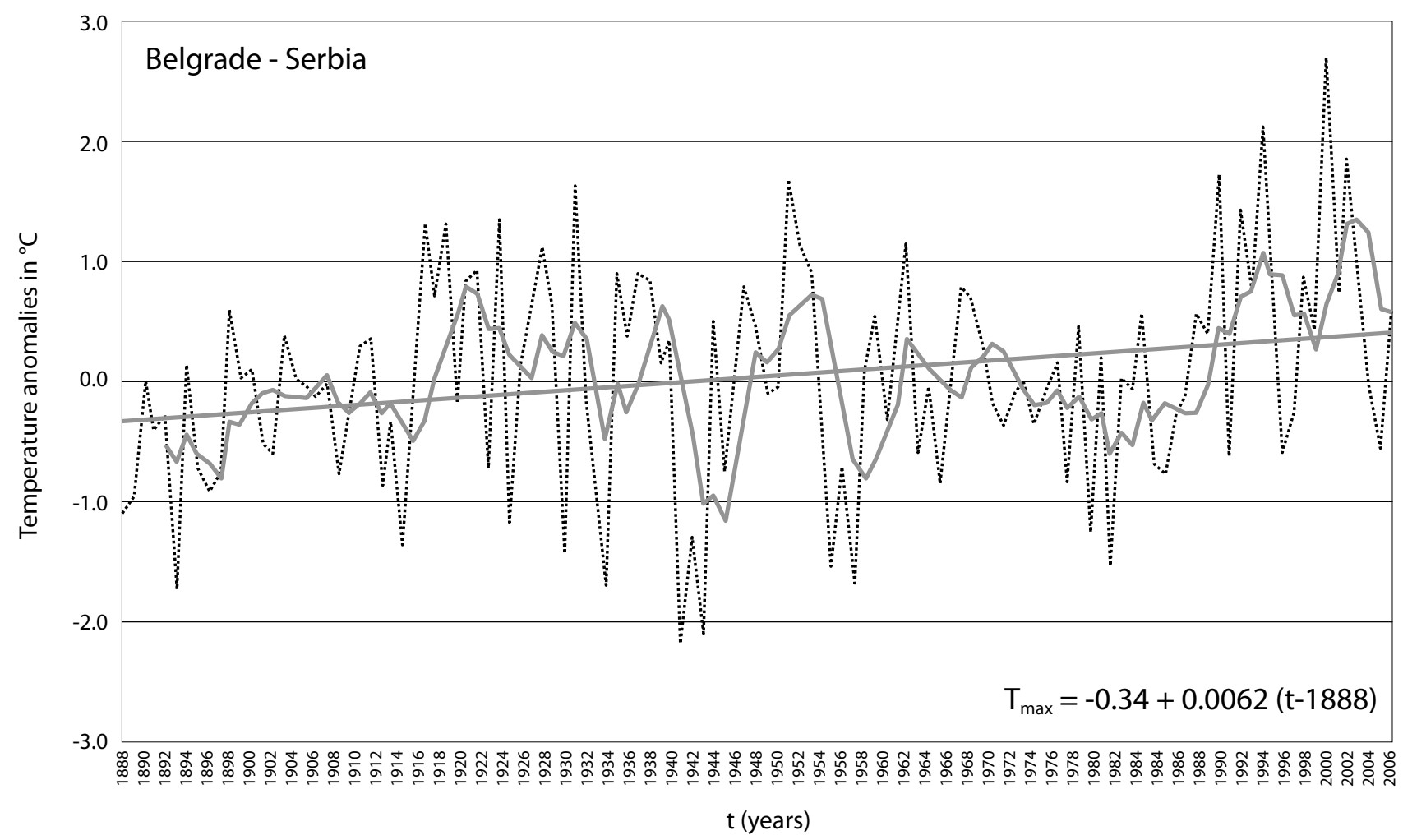

Figure $\mathbf{1 b}$ Deviation, 5-year moving means and deviation trends of annual maximum temperature for Belgrade for the period $1888-2006$

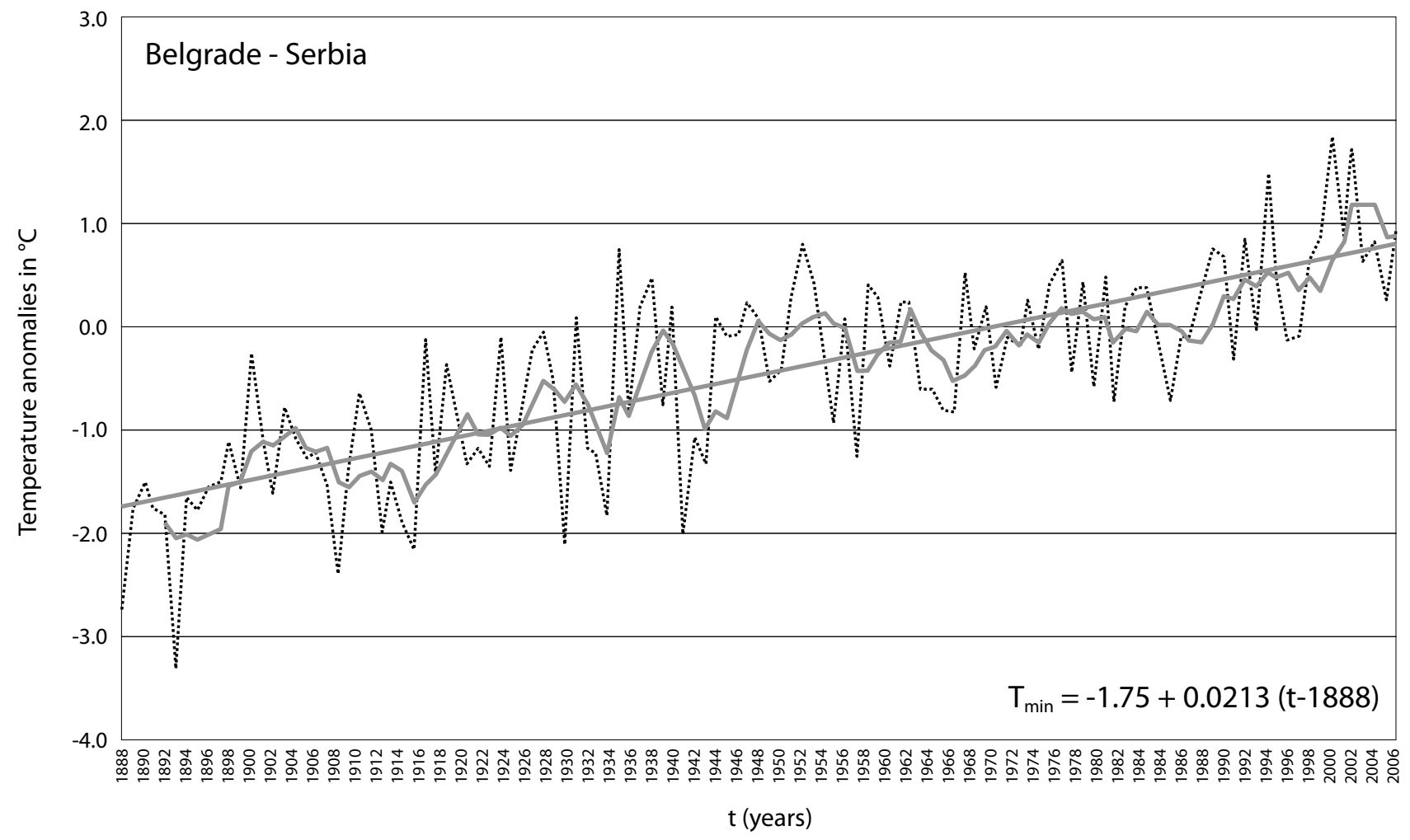

Figure 1c Deviation, 5-year moving means and deviation trends of annual minimum temperature for Belgrade for the period $1888-2006$

\section{Belgrade - Precipitation}

Deviation of annual precipitation quantities and the number of days with precipitation $\geq 0.1 \mathrm{~mm}$ from the basic period 1961-1990 are presented on two panels using pillars on Figure 2 going downwards in order. As in Figure 1, black curves show 5-year moving means, and straight lines are precipitation trends. Also, trend equations are given where
$\mathrm{R}$ and NBR for annual precipitation quantity and number of days with precipitation $\geq 0.1 \mathrm{~mm}$. Again, precipitation trend coefficient serves as the assessment of precipitation change tendency.

Positive coefficient trend is evident for annual precipitation quantity in the amount of $+8.9 \mathrm{~mm} / 100$ years and negative for the number of days with precipitation in the 


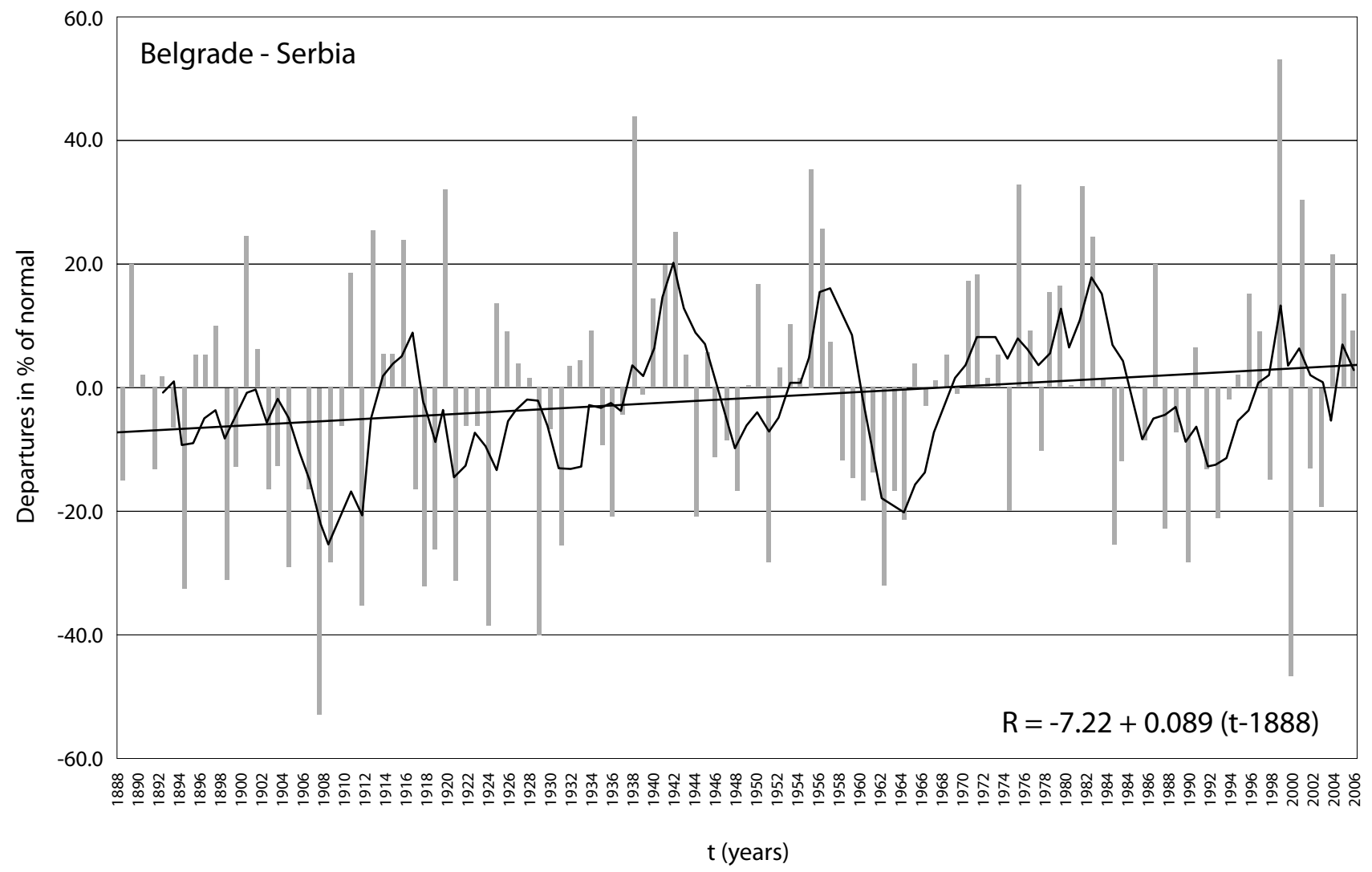

Figure 2a Deviation, 5-year moving means and deviation trends of annual precipitation quantity for Belgrade for the period 1888-2006

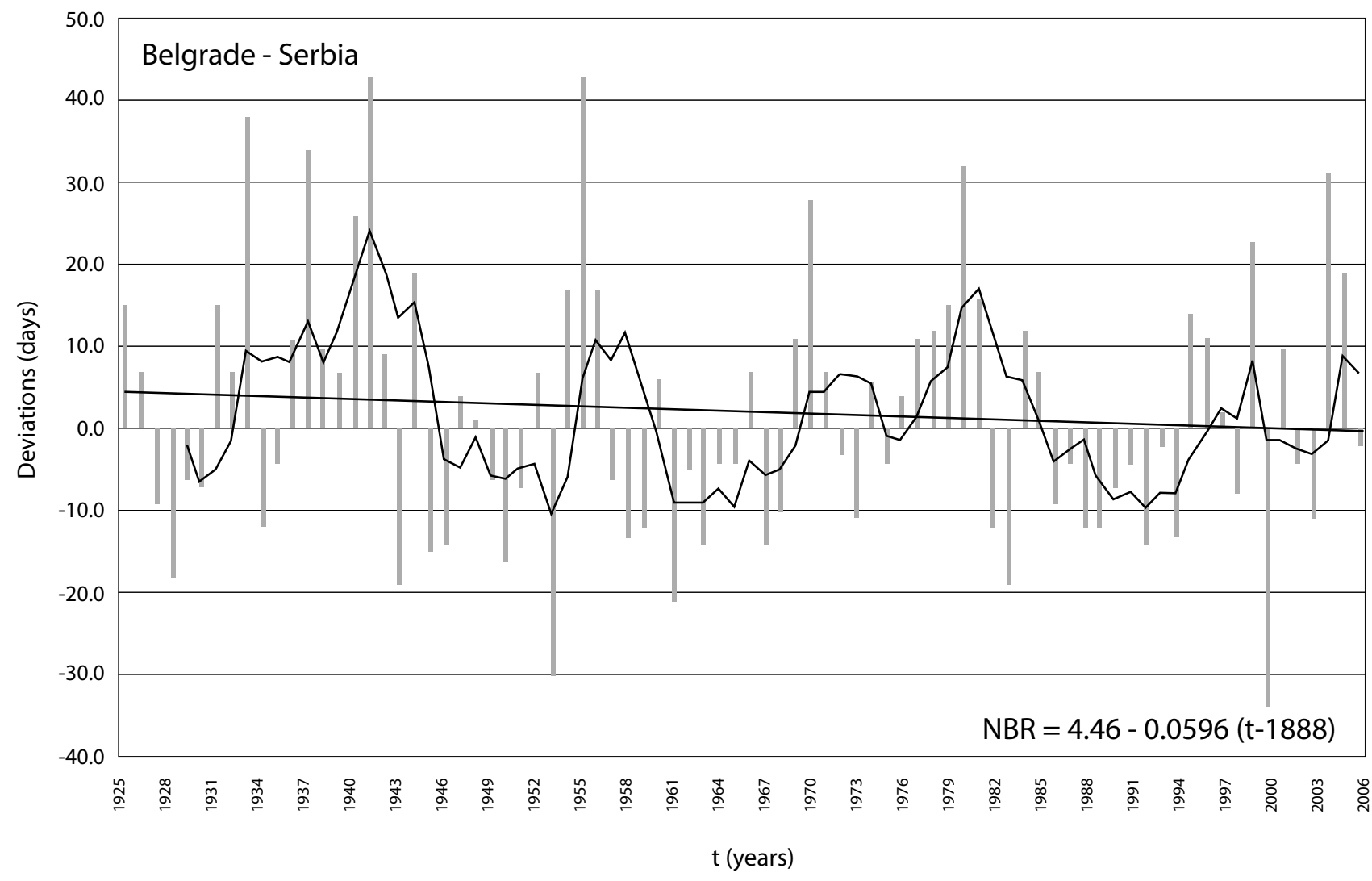

Figure $\mathbf{2} \mathbf{b}$ Deviation, 5-year moving means and deviation trends of number of days with precipitation $\geq 0.1 \mathrm{~mm}$ for Belgrade for the period 1888-2006 
Table 3 Deviation trend coefficients as per seasons of precipitation quantity and number of days with precipitation $\geq$ $0.1 \mathrm{~mm}$ in Belgrade in the period of 1888-2006

\begin{tabular}{|l|c|c|}
\hline Seasons & $\begin{array}{c}\text { Precipitation } \\
\text { (mm/100 years) }\end{array}$ & $\begin{array}{c}\text { Number of days } \\
\text { with precipitation } \\
\text { (days/100 years) }\end{array}$ \\
\hline Spring & -8.0 & -0.9 \\
\hline Summer & +16.3 & +1.2 \\
\hline Autumn & +0.6 & -3.0 \\
\hline Winter & +27.4 & -3.2 \\
\hline
\end{tabular}

amount of -6 days/10o years. Thus, in observed period, annual precipitation quantity has increased and the total number of days with precipitation has decreased. Although the number of days with precipitation is lower, increased precipitation intensity contributed to higher total annual precipitation quantity.

Trend coefficients as per seasons (first column), the deviation of precipitation amount (second column) and the number of days with precipitation $\geq 0.1 \mathrm{~mm}$ (third column) are shown in this order in Table 3. Precipitation trend coefficient is negative only in spring, while positive in other seasons. Thus, precipitation is decreased in spring months, while in other parts of the year precipitation is increasing, mostly during winter by $\mathbf{2 7 . 4} \mathrm{mm} / \mathbf{1 0 0}$ years. For the number of days with precipitation, the trend coefficient is positive only in summer, while negative in other seasons. Thus, the number of days with precipitation is increased in summer months, while it is decreasing in other parts of the year, mostly during winter by -3.2 days/10o years.

\section{Serbia - Temperature}

Temperature changes in Serbia for the period 1957-2006 were observed on 15 stations: Sombor, Kikinda, Novi Sad, Beograd, Veliko Gradište, Loznica, Smederevska Palanka, Negotin, Zaječar, Ćuprija, Kraljevo, Zlatibor, Kruševac, Niš, Sjenica, Dimitrovgrad and Vranje. For that purpose the following indicators of changing extremes were calculated: Tn9o, Tn10, Tx9o, Tx10, HWDI and TxGE30. They are shown in this order in six maps marked from a) to $\mathrm{f}$ ) in Figure 3 (Vincent and Mekis, 2004). The circles on maps denote stations. Their colors mean: red, the increase in frequency of very high values and decrease in frequency of very low values of extreme temperatures, i.e., warming trend; and blue, the decrease of frequency of very high and the increase in frequency of very low extreme temperature, i.e., cooling trend.

The results show that more stations have changed in their cold and warm extremes. On major number of stations negative trends were obtained of minimum temperatures with values lower than the $10^{\text {th }}$ percentile. The greatest trend decrease of $-61 \% / 50$ years was obtained for Novi Sad, then $-52 \% / 50$ years for Beograd, Figure $3 a$. Thus, on these stations, occurrence frequency of very low temperature has decreased. Nonetheless, on the stations Veliko Gradište, Vranje, Zaječar and Dimitrovgrad positive trends of minimum temperatures were recorded which means that on them the occurrence frequency of very low temperature has increased.

Besides that, on all the stations, except in Vranje, positive trends were obtained of minimum temperatures with the values higher than the $90^{\text {th }}$ percentile. Major increase of $+144 \% / 50$ years was obtained for Kikinda, then $+137 \% / 50$ years for Beograd, Figure $3 \mathrm{~b}$. Thus, on these stations the occurrence frequency of very high minimum temperature is increased, while in Vranje it is decreased.

Negative trends of maximum temperatures whose values are lower than the $10^{\text {th }}$ percentile were obtained on all the stations, except in Dimitrovgrad. The highest decrease of $-58 \% / 50$ years was obtained for Zaječar, Figure 3c. Thus, on these stations there was a decrease in the occurrence frequency of very low maximum temperature, while in Dimitrovgrad this frequency increased.

Also, on all the stations positive trends were obtained of maximum temperatures whose values are higher than the $90^{\text {th }}$ percentile. The highest rise of $+173 \% / 50$ years was obtained for Zlatibor, Figure $3 \mathrm{~d}$. Thus, the occurrence fre quency of very high maximum temperature was increased.

Statistically significant changes were noticed with heat waves which became more frequent and lasted longer. On all the stations positive trend of climate indicator HWDI was obtained, Figure 3e. The highest trend increase of +106 $\% / 50$ years was obtained for Negotin. Thus, the occurrence frequency increased of the periods with consecutive very high maximum temperatures, so-called heat waves.

Finally, positive trend of climate indicators TxGE3o was obtained on all the stations, Figure $3 \mathrm{f}$. The greatest trend in crease of +46 days $/ 5$ oyearswas obtained forSombor. Thus, the numberofdaysincreased withmaximum temperature $\geq 30^{\circ} \mathrm{C}$ so-called tropical days.

\section{Serbia - Precipitation}

Changes in precipitation regime in Serbia were observed on 19 stations: Sombor, Kikinda, Novi Sad, Sremska Mitrovica, Beograd, Veliko Gradište, Loznica, Smederevska Palanka, Negotin, Zaječar, Kragujevac, Ćuprija, Kraljevo, Požega, Zlatibor, Kruševac, Niš, Dimitrovgrad and Vranje for the period 1961-2006. For that purpose, precipitation indicator of changing extremes R95T was calculated. It is shown for each of the stations in Figure 4. The circles denote stations and colors denote the following: red, the increase in frequency of very high precipitation quantity, and blue, the decrease in frequency of very high precipitation quantity.

The results of precipitation analysis indicate that climate events with extremely high precipitation quantity (greater than the $95^{\text {th }}$ percentile) are all the more frequent on the stations: Beograd, Zlatibor, Kikinda, Sombor, Kragujevac, Loznica, Smederevska Palanka, Požega, Novi Sad, Niš and Ćuprija. On all other stations such events are becoming less frequent.

\section{Conclusion}

Climate changes in Belgrade were observed for the period 1888-2006 by the analysis of temperature and precipitation. It was shown that the mean, maximum and minimum annual and seasonal air temperatures have risen, except during summer when maximum temperature had the tendency of slight decrease. The greatest increase was noticed with minimum temperature, especially in winter. On annual level, precipitation quantities are increasing, with the highest increase in winter, while in spring they are decreasing. 

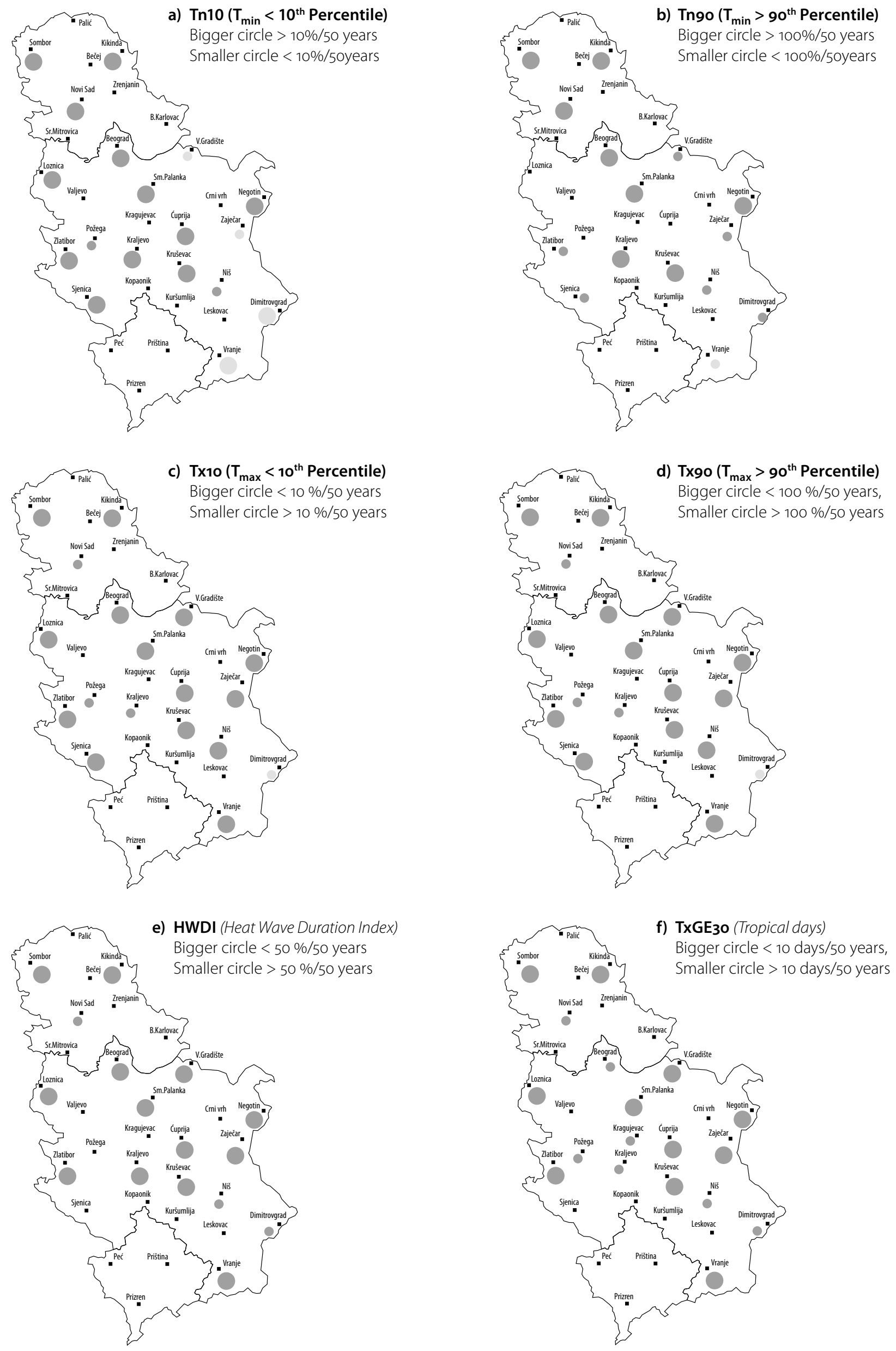

Figure 3 Trends in six temperature indices during 1957- 2006 


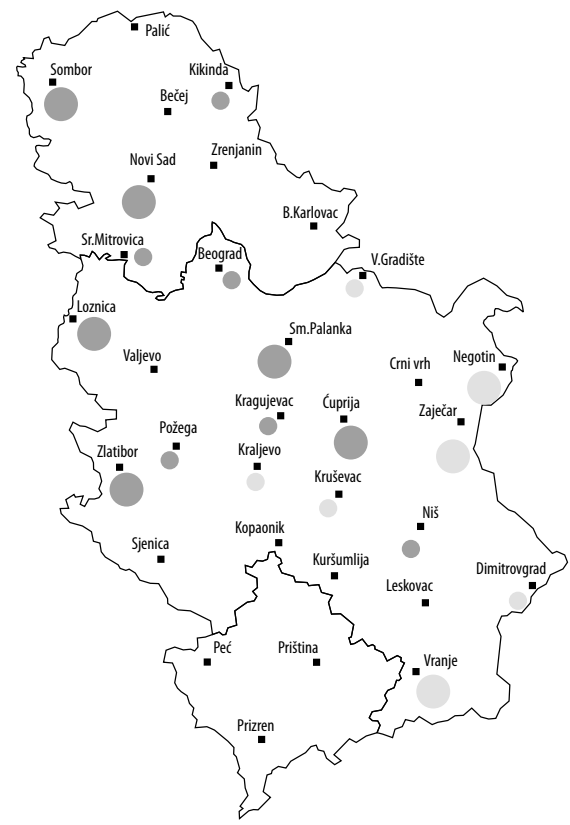

Figure 4 Trends in precipitation indices R95T during 1961- 2006

During the year, the number of days with precipitation is decreasing, except in summer when the increased number of such days was recorded.

Climate changes in Serbia were observed on 15 temperature stations in the period 1957-2006 and on 19 precipitation stations in the period of 1961-2006 by analysing indicators of changing extremes (Peterson, et al., 2001). On the stations Sombor, Kikinda, Novi Sad, Beograd, Loznica, Smederevska Palanka, Negotin, Ćuprija, Kraljevo, Zlatibor, Kruševac, Niš and Sjenica, the occurrence frequency of very low temperature decreased, while on other stations, this frequency increased. On all the stations, the occurrence frequency of very high minimum temperature increased, while in Vranje it decreased. In Dimitrovgrad, the occurrence frequency of very low maximum temperature increased, while on other stations this frequency decreased. The increase of the frequency of very high maximum temperature was obtained on all the stations where the occurrence frequency of heat waves and tropical days increased. The frequency of extremely high precipitation quantity increased on the stations: Beograd, Zlatibor Kikinda, Sombor, Kragujevac, Loznica, Smederevska Palanka, Požega, Novi Sad, Niš and Ćuprija. On other stations, such events are becoming less frequent. Similar results for temperature and precipitation were obtained for seven stations (Sarajevo, Podgorica, Uljcinj, Tirane, Prilep, Athens, Corfu) from the area of Southeastern Europe for the period 1955-200o (Djukić, et al., 2008).

\section{References}

IPCC, 2007. Climate Change 2007. The Physical Science Basis. Contribution of Working Group I to the Fourth Assessment Report of the Intergovernmental Panel on Climate Change [Solomon, S., D. Qin, M. Manning, Z. Chen, M. Marquis, K.B. Averyt, M. Tignor and H.L. Miller (eds.)]. Cambridge University Press, Cambridge, United Kingdom and New York, NY, USA: 996 pp.

Djordjević, S. 2002. Research on changing climate in Belgrade 1951-2000. $18^{\text {th }}$ International Conference on Carpathian Meteorology, Belgrade, 7-11 October 2002.

Djordjević, S., Jovanović, G. 2006. Trends and frequency of heat waves and tropical days in Serbia. International Conference on the Problems of Hydrometeorological Security, Moscow, Russia, 26-29 September 2006.

Djukić, D., Djordjević, S., Smailagić, J., Mihajlović, M., Jovanović, G. 2008. Trends of some climate elements in the Southeastern Europe. Republic Hydrometeorological Service of Serbia, 76 p. (in Serbian).

Jovanović G., Djordjević, S. 2006. The Analyses of Minimum Air Temperatures in Serbia. International Conference on the Problems of Hydrometeorological Security, Moscow, Russia, 26-29 September 2006.

WMO, 1983. Guide to Climatological Practices. WMO, no.10o, Geneva, Switzerland.

Vincent A. L., Mekis, E. 2004. Variations and trends in climate indices for Canada. $15^{\text {th }}$ Symposium on Global Change and Variations, Seattle, Washington, January 1115, 2004.

Peterson T., Folland C., Gruza G., Hogg W., Mokssit A., Plummer N., 2001. Report on the activities of the working group on climate change detection and related rapporteurs. WCDMP, no. 47, WMO-TD, no. 1071. 